\title{
The Relationship between Internet Marketing Paybacks and Firm Productivity: Perspectives from Zimbabwean SMEs
}

\author{
N.Dlodlo \\ C. Mafini \\ Faculty of Management Sciences, Vaal University of Technology \\ Private Bag X021, Vanderbilpark, 1900 \\ Email: nobukhosid@vut.ac.za, chengedzai@hotmail.com
}

\section{Doi:10.5901/mjss.2014.v5n8p21}

\begin{abstract}
This study sought to explore the influence of internet marketing benefits among SMEs in Zimbabwe. Specifically, the study aimed at identifying the paybacks (benefits) emanating from the adoption of Internet marketing as well as examining the relationship between these benefits and SME productivity. A structured survey questionnaire was administered to a conveniently selected sample of 189 SMEs in the two largest cities of Zimbabwe; namely, Harare and Bulawayo. Using exploratory factor analysis, four factors; namely, intelligence gathering, promotion, communication and customer relationship management were extracted. Mean scores and standardized Z-values revealed that promotion was the most important among the extracted factors. Pearson correlation tests showed strong positive relationships between SME productivity and two factors which are intelligence gathering and promotion. SME productivity and communication were moderately associated while the relationship between SME productivity and customer relationship management was weak. Intelligence gathering, promotion and communication emerged as statistically significant predictors of SME productivity.
\end{abstract}

Keywords: Internet Marketing, Paybacks, Benefits, Productivity, SMEs, Zimbabwe

\section{Introduction and Background}

Small and Medium Enterprises (SMEs) have emerged as a major source of innovation and development in many developing and fast growing transition economies. This could be attributed to the fact that the SME sector is by far the largest contributor to the stimulation of competition, bringing about a diversity of products and services, and delivering flexibility in the internal and external systems (Kendall et al., 2001). In the same vein, SMEs may be considered as the lifeblood of modern economies (Rao et al., 2003), creating far more jobs than those created by large businesses (Soontiens, 2002) and making a significant contribution to global economic growth (Jutla et al., 2002).

The recent changes in the Zimbabwean economy, particularly the dollarization progression; the nationalisation of mines as well as the indegenisation programmes being promoted by the existing government have contributed to the proliferation of SMEs in all sectors of the economy (Mutambanengwe, 2012). In addition, the soaring high unemployment levels in Zimbabwe since the introduction of the Economic Structural Adjustment Program (ESAP) in 1991resulted in the loss of jobs, shrinking of the formal job market and the impoverishment of people, thereby creating conditions for the increase of SMEs (Moyo, 2010). The land reform programme also had a serious impact on companies operating in the agricultural sector and in particular, SMEs. The Indigenisation Bill which promulgated the transfer of $51 \%$ shares from the big international companies to indigenous people created a wave of uncertainty and disinvestment, adding to the high levels of unemployment and the creation of more unstable SMEs (Tsikirayi et al., 2013). By 2010, Zimbabwe's unemployment rate had hiked to $94 \%$, which meant that only a few people were formally employed and the rest were in the SME sector (CZI Business Intelligence Report, 2010). Therefore, SMEs play a critical role in respect of both output and employment.

Beaver (2002) observed that there is no universal definition of SMEs. The technical definition of SMEs varies from country to country and industry to industry, depending on the size of the economy. Beaver (2002) further suggests that a small business can be defined either qualitatively or quantitatively. Qualitative classification defines SMEs in terms of ownership whereas defining it quantitatively is done to the number of employees, owner's equity, annual turnover or revenues and asset value. In Zimbabwe, small enterprises are those companies that have turnover of less than US\$100 000 or assets less than US\$100 000 while medium enterprises assets are between US\$240 000 and US\$1 million 
(Republic of Zimbabwe, 2002). The SME sector comprises of between $1-300$ employees in most countries though their size is even smaller in developing countries. In addition, it may be noteworthy to state that SMEs classification is merely for administrative purposes by industrial associations because SMEs are not homogeneous but vary greatly in size, structure, complexity and activities.

World over, SMEs are known to contribute at least 50\% of the GDP and produce most of the world's output (Burgess and Bothma, 2007). In recent years, much attention and support has been aimed at improving productivity while considerably reducing the failure rates of these firms. The Zimbabwean Government and private sector aim to transform SMEs into large corporations or at least more profitable business entities with a view to enhance the output of the formerly under-privileged black people (Black Economic Empowerment) (Moyo, 2010). As part of this national and global move, the deregulation and pervasive use of Information Technology (IT) has led to the commercialisation of the Internet as a key enabler for a networked economy (Lewis and Cockrill, 2002). More significantly, the Internet has led to the opening of markets and global trade expansion among local and international businesses (Moodley, 2003). This platform has presented priceless benefits for SMEs that seek to influence the formation of a particular brand, brand image and consequently brand equity (Biedenbach and Marell, 2009). As acknowledged by Mutambanengwe (2010), the creation of synergies across media may also be adopted in order to produce additional uplift. This can be achieved through tailoring marketing and promotional messages with specific Internet based media. Therefore, virtual information is now a wealth creating asset for businesses seeking to deliver value business and extend their online presence (Hasnu and Amjad, 2006). These apparent configurations suggest that the adoption of Internet marketing strategies can go a long way in representing the SME sector in any national economy.

Internet marketing may be perceived as the use of electronic data and applications for planning and executing the conception, distribution, promotion and pricing of ideas, goods and services to create exchanges that satisfy individual and organisational objectives (Gohary, 2007). Hongyu and Dongmei (2011) further define Internet Marketing as a new way of marketing that is based on the Internet through the use of digital information and online media, with a view to create, disseminate and transfer customer value. The terms Internet marketing, electronic marketing and E-Marketing have been used interchangeably in this study. This is because Internet marketing entails the range of marketing activities for products and services using Internet technology among all kinds of actors; among consumers (C2C), among businesses (B2B) and between businesses to consumers (B2C) (Pires and Aisbett, 2003). Such technology-based marketing practices improve and transform the conduct of marketing functions (Zappalla and Gray, 2006).

Internet usage started mainly as a means of communication, by such modes as E-mail and for providing information via online news and home pages on the web (Drew, 2003). It was also used to provide valuable linkages for critical social and economic activities through information sharing (Sharma and Arya, 2006). Several firms adopted the technologies initially for the achievement of marketing objectives through Mobile marketing and SMS marketing which is a subset of e-marketing and the use of electronic communications technology (Bamba and Barnes, 2007). Therefore, electronic marketing enables marketers to reach more customers and potentially increase total share of the market (Lee and Cheung, 2004).

\subsection{Internet Marketing Paybacks among SMEs}

The benefits associated with Internet marketing among SMEs have received empirical attention in the past. For example, Melewar and Smith (2003) found that the Internet may enhance the ability of SMEs to identify and evaluate international competitors apart from developing networks of contacts and partners in foreign markets. The same authors further suggest that the Internet enables marketing firms to communicate and gather information on both customers and suppliers in the most cost-efficient manner possible. This is usually as a result of the timeless virtual presence of the firm and its related brands 24 hours a day and 365 days a year. Such anytime anywhere access ultimately leads to increased convenience on the part of the SME owners as well as the customers (Simpson and Docherty, 2004). In addition, the boundaries of time and space are eliminated through Internet adoption and this plays a considerable role among most SMEs which seek to pursue a growth strategy (Sheth and Sharma, 2005). The Internet is therefore a critical factor in the enhancement of any firm's market reach and operational efficiency (Dholakia and Kshetri, 2004; Klerk and Kroon, 2005).

Another benefit associated with Internet marketing is the elimination of costs associated with utilising traditional intermediaries through a process called disintermediation (Klerk and Kroon, 2005; Chong et al., 2011). This is a critical factor among SMEs that are often presented with an urgent need to increase productivity and accomplish goals faster. In addition, cost-savings may be realised through the elimination of paper and reduction of delays in the sales turnaround time, which is typical of traditional business practices (Daniel and Wilson, 2002; Mutula, 2002). In this manner, Internet marketing serves to level the playing field between SMEs and larger businesses in various industries with smaller firms 
obtaining more power in the markets through online presence (Klerk and Kroon, 2005). Ultimately, SMEs should ensure that their Internet marketing practices are aligned with their strategic goals and in turn create positive outcomes for the organisation (Beheshti and Sangari, 2007).

\subsection{The importance of Internet marketing in developing SME Productivity}

A study conducted by Hongyu and Dongmei (2011) suggests that the advent of the Internet has changed the global business and marketing landscape. The Internet accounted for 10\% of GDP growth over the past 15 years (Varadarajan and Yadav, 2009). Recent ICT developments like Enterprise 2.0, cloud computing, social networks, etc. are enabling dynamic, new and smaller companies to develop and bring marketing innovations that before were too expensive to develop. In this manner, various information technologies have been mobilised to cut across all industries and create wealth, jobs and growth for the SME sector through the adoption of technology as a lever for modernizing the traditional marketing communication mix (Kotler, 2006). Smart innovations that are Internet-enabled or powered by recent ICT developments often lead to higher productivity and have significantly benefited all industries (Ueno, 2006). Internet marketing technology also plays a major role in empowering the push toward key account management, communicating with both internal and external stakeholders in real-time as well as promoting various products and services etc. Ultimately, this enables SMEs to remain competitive, relevant and possibly remain on the same leverage as their larger counterparts (Soontiens, 2002).

\section{Problem Statement}

The significant presence of Zimbabwean SMEs in both densely populated commercial and residential areas mechanically predisposes this sector to virtual marketing platforms that will facilitate social presence of these businesses anytime and anywhere. Moreover, the importance of the Internet as a tool to support promotional communication and marketing activities by SMEs in their business networks is widely accepted and has seen growing interest as a subject of investigation in entrepreneurship research (Loane, 2005). However, SMEs are dependent on a clear understanding of the pertinent paybacks of this innovative technology to foster the adoption process. In short, there is scope to expand the existing literature within a Zimbabwean context.

The research area of SME Internet marketing benefits is still in its infancy, with a majority of the studies having been conducted in western countries (Chong et al., 2011). In addition, the literature to date on electronic marketing benefits is largely anecdotal. Similarly, at any time, many of the SMEs are relatively new and may not have properly structured in-house Marketing departments or IT specialists to integrate the online marketing practices. In addition, Small firms in developing countries have received very little attention from management science researchers, leading to a paucity of research focusing on Internet marketing activities within the flourishing SME sector (Tsikirayi et al., 2013). This dearth of academic publications on SMEs in Zimbabwe makes the diffusion and adoption benefits of various Internet marketing practices difficult to assess. Furthermore, despite the significant contribution of SMEs toward the Gross Domestic Product (GDP) growth of many countries and the development of improved standards of living for the general citizenry, there have been very few studies conducted in relation to the relevance, significance and potential paybacks of Internet based marketing communications in the context of SMEs (Asli Demirguç-Kunt and Maksimovic, 2005). To this end, current efforts and respective tools that are predominantly used in web 2.0 online promotional campaigns are usually best-suited for larger enterprises owing to the large infrastructural investments associated with adopting such electronic marketing activities (Kotler, 2006). This scenario may have been transformed over the years but is still the case in the context of SMEs in Zimbabwe.

It is also noteworthy to attest that the benefits of Internet Marketing have been realised in developed countries such as New Zealand (Ramsey and McCole, 2005) and Australia (Berril et al., 2004) as well as in developing nations such as Chile (Grandon and Pearson, 2003); China (Morgan et al., 2006) and Malaysia (Mukti, 2000). This study seeks to validate whether similar or dissimilar paybacks to those enjoyed by their international counterparts have been realised within the context of Zimbabwean SMEs and also establish the extent to which the identified paybacks have contributed towards overall productivity of the small and medium enterprise sector.

\section{Purpose of the Study}

To date Zimbabwean SMEs still do not have an appropriate legal framework in which to conduct their businesses. More specifically, due to a lack of skills and technological resources, marketing operations in the sector depends primarily on 
the knowledge of the director or owner rather than through written rules, regulations and agreements. Therefore, the pertinent paybacks that may be linked to the implementation of Internet marketing strategies may not be apparent or understood by some. The primary purpose of this study was to identify the benefits that are associated with Internet marketing adoption by SMEs in Zimbabwe. The secondary purpose of this study was to examine the relationship between these Internet marketing benefits and SME productivity.

\section{Methodology}

In this study, the quantitative design, using the self administered survey method was adopted. A survey method was deemed appropriate because it enables easier administration of accurate data (Welman and Kruger, 1999).

\subsection{Sample}

Databases belonging to three Zimbabwean government institutions; namely, The Ministry of Small and Medium Enterprises and Cooperative Development (MSMECD), Zimbabwe Trading Association (ZimTrade) and National Social Security Authority (NSSA) and the Small and Medium Enterprises Association of Zimbabwe (SMEAZ) were used to generate a sample size of 300 formally registered small and medium sized enterprises. This sample size is in line with previous research on SME development (Biedenbach and Marell, 2009; Tsikirayi et al., 2013; Hongyu and Dongmei, 2011). Participants were drawn on a convenience basis from six prominent SME business parks and commercial areas in two major cities of Zimbabwe; namely, Harare (Willowvale, Southerton and Masasa) and Bulawayo (Kelvin North, Belmont and Khami industrial area).

Only those individuals; both males and females older than 18 years; who were either SME managers, owners, IT specialists or Marketing personnel who were actively engaged in the online promotions of the company's brand were selected because it was believed that they could offer valuable contributions to the research questions. Consequentially, inclusion-exclusion criteria were employed in the study by incorporating only those users who had some 'minimum experience' within Internet-based marketing, rather than those without such experience. This was done in order to facilitate the external validity of this study.

\subsection{Instrumentation and data collection}

A three stage design was used to generate the items that were to be included in the construction of the scale. The first stage involved an analysis of previous studies on Internet marketing benefits among firms. This was conducted with a view to establish Internet marketing benefits that have the consistent support of previous literature. Consequently, a number of previous scales (Daniel and Wilson, 2002; Harrisn and Waite, 2006; Kohn and Husig, 2006; Beheshti and Sangari, 2007) were identified and used as reference points in the generation of the items used in the study. In the second stage, the developed scale was reviewed by three academics whose fields of expertise lie in the discipline on online marketing. This was carried out primarily to check the content validity of the questionnaire. Additionally, the pretest also served to determine the anticipated questionnaire completion time. Finally, a pilot study using a conveniently selected sample of 30 SME Managers located in the Willowvale area of the city of Harare was also conducted prior to the main survey. However, in order to evade data contamination and bias, the responses from the pilot test were excluded from the main survey. Based on feedback from the pilot study, minor revisions were made to the questionnaire. This helped to affirm that the questionnaire used in the main survey would validly capture the information sought by the researchers.

The questionnaire was divided into three sections. Section A sought to elicit demographic information from SME managers while Section B sought information on the profile of the SMEs under survey. Section C requested information on SME owner-managers' views on the benefits of Internet marketing to SMEs. The items in section C were scored on a 7-point Likert scale which ranged from 1 (strongly disagree) to 7 (strongly agree). Each questionnaire was anchored by an introductory letter citing the names of the researchers, study objectives, organisation details and ethical considerations for participating in the study. A total of 300 questionnaires were administered by the researchers to the SMEs operating in the identified locations. Due to the limited co-operative efforts of the SME managers and busy schedules of their IT specialists, only 189 questionnaires were returned and considered usable for the study giving an acceptable response rate of $63 \%$.

Data were collected with the assistance of three trained fieldworkers, who were supervised by the principal researcher. To notify targeted respondents, physical visits in place of the traditional phone calls to the companies were 
made. Some questionnaires were administered on first visit but most were administered after scheduling an appointment which required 3 or more follow-up visits. Since it is also paramount that research be conducted in an ethical manner, respondents were informed that participation was strictly voluntary and that the research was solely for academic purposes. Furthermore, the respondents' right to anonymity, confidentiality, privacy or informed consent as well as protection from discomfort, harm and victimisation were followed during the process of data collection.

\subsection{Reliability and validity}

In the study, the reliability coefficients for the overall Internet marketing benefits scale and its individual dimensions were computed with a view to verify the internal consistency among the variables that had been adapted from several previous studies. As a rule of thumb, Malhotra (2010) recommends that Cronbach's alpha values ranging between 0.60 and 0.69 be considered as acceptable whilst values above 0.70 are deemed as adequate. In this case, the individual coefficient alpha values for the subscales ranged between 0.702 and 0.810 while a Cronbach alpha of 0.708 was computed for the overall Internet Marketing benefits scale (refer to Table 1). These values attest to acceptable internal consistency and homogeneity of the scales used in this study.

Content and face validity of the instrument was ascertained through pre-testing the questionnaire with a conveniently selected sample of twenty respondents. As mentioned previously, the questionnaire was also reviewed by three academics who are experts in the field of online marketing. Construct validity of the scale was assessed through exploratory factor analysis (EFA). The results indicated that there were no cross-loadings among constructs; leading to the extraction of five pertinent internet marketing paybacks. The acceptable Cronbach alpha values obtained as well as Pearson's correlation tests conducted (refer to Table 3) served as enduring indicators of convergent validity in the scale (Maxwell and Moores, 2007). Predictive validity was measured through regression analysis. Causality was explained by three of the four Internet marketing paybacks with SME productivity (refer to Table 4).

\subsection{Data analysis}

Data analyses were conducted using the Statistical Package of the Social Sciences (SPSS version 21.0). Simple frequencies were used to analyse the demographic profile of respondents. Exploratory factor analysis was employed to identify the Internet marketing payback factors. Measures of central tendency were then used to compare the importance of each of the factors. Pearson's rho was utilised to examine the relationship between Internet marketing payback factors prior to the application of linear regression analysis to measure causality between SME productivity and the extracted Internet marketing payback factors.

\section{Results}

\subsection{Demographic profile of the respondents}

In the study, each one of the 189 SMEs had been in existence for at least two years and was represented by a single respondent. Approximately $76 \%(n=144)$ of the businesses were classified as small enterprises and $24 \%(n=45)$ were classified as medium enterprises. This classification was based on the number of employees and the annual turnover of each business respectively; with small businesses having a staff complement of less than 50 full-time employees and operating on less than USD 100000 annual turnover. The medium businesses were those that were composed of between 51 and 200 employees and had an annual turnover of at least USD 240000 . This segmentation criterion is in line with the Republic of Zimbabwe SME development Framework (2002). A majority of the respondents (64\%; $n=121$ ) were male whereas $36 \%(n=68)$ were female. In terms of age groups, approximately $61 \%(n=115)$ were aged between 20 and 40 years. With reference to academic qualifications, most of the respondents $(71 \% ; n=134)$ held at least a college diploma.

\subsection{Internet marketing paybacks}

The Internet marketing paybacks extracted in the study consisted of four dimensions; namely, intelligence gathering, promotion, communication and customer relationship management. These factors were computed through exploratory factor analysis. The naming of the factors as well as the psychometric properties of the factors are reported in Table 1. 
Table 1: Internet marketing paybacks dimensions, psychometric properties and description of dimensions

\begin{tabular}{|c|c|c|c|c|}
\hline Factor & $\begin{array}{l}\text { Number } \\
\text { of Items }\end{array}$ & $\begin{array}{l}\text { Percentage of } \\
\text { variance } \\
\text { explained }\end{array}$ & $\begin{array}{l}\text { Cronbach } \\
\text { alpha }\end{array}$ & Description \\
\hline $\begin{array}{l}\text { Intelligence } \\
\text { gathering }\end{array}$ & 8 & 18.7 & 0.755 & $\begin{array}{l}\text { This refers to the use of Internet marketing in gathering information on various important } \\
\text { strategic constituencies as well as developments in the operational environment } \\
\text { This factor describes the role of Internet marketing as a promotional tool through the }\end{array}$ \\
\hline Promotion & 6 & 21. 8 & 0.810 & $\begin{array}{l}\text { enhancement of SME brand awareness at both local and international frontiers, } \\
\text { differentiation of supplier's products from those of competitors as well as delivering } \\
\text { customer convenience that is neither restricted by time nor space }\end{array}$ \\
\hline Communication & 6 & 13.7 & 0.747 & $\begin{array}{l}\text { This refers to the use of Internet marketing as a medium for the exchange of information } \\
\text { between an organisation and its stakeholders }\end{array}$ \\
\hline $\begin{array}{l}\text { Customer } \\
\text { relationship } \\
\text { management }\end{array}$ & 4 & 7.9 & 0.702 & $\begin{array}{l}\text { This refers to the use of Internet marketing as a tool to manage the relationship between an } \\
\text { enterprise and its customers. }\end{array}$ \\
\hline SME Productivity & 7 & $\mathrm{~N} / \mathrm{A}$ & 0.724 & $\begin{array}{l}\text { This outcome variable describes how business productivity (output) may be improved } \\
\text { through the adoption of Internet marketing programmes }\end{array}$ \\
\hline
\end{tabular}

The total variance explained by the extracted factors is 62.1 , which indicates that $37.9 \%$ is accounted for by extraneous variables that do not constitute part of this study. The promotion factor contributed the highest percentage of variance explained, which signifies its importance as an Internet marketing benefit factor.

\subsection{Mean Scores of the Internet Marketing benefits' dimensions}

Mean rankings which compare the importance of the Internet marketing factors relative to each other are reported in Table 2. The minimum and maximum values are based on the lowest (1) and highest (7) values in terms of the sevenpoint Likert scale that was anchored by strongly disagree $=1$ to strongly agree $=7$. The means were calculated by summating the response values of variables that comprised each sub-scale divided by the number of variables on each dimension. In addition, a one-tailed z-test was performed to determine whether these computed means are significant. The expected mean was set at 3.5 and the significance level at either the conventional $p<0.01$ or $p<0.05$ (Table 2)

Table 2: Descriptive statistics_Internet Marketing benefits and SME productivity

\begin{tabular}{lccccc}
\hline Dimension & Mean Scores $(\bar{x})$ & Standard Deviation & Standard error & Z-Score & Sig (P-value) \\
\hline Intelligence Gathering & 5.579 & 1.449 & 0.057 & 2.869 & $.021^{*}$ \\
\hline Promotion & 5.924 & 2.585 & 0.070 & 1.961 & $.000^{\star *}$ \\
\hline Communication & 5.650 & 1.052 & 0.069 & 2.302 & $.046^{\star}$ \\
\hline Customer relationship management & 5.051 & 1.094 & 0.048 & 1.479 & $.013^{*}$ \\
\hline SME Productivity & 5.826 & 0.998 & 0.073 & 1.148 & $.009^{\star *}$ \\
\hline Minimum mean value= 1 and Maximum mean value=7, ${ }^{*}$ "Significant at $p<0.05$ (one-tailed) & & \\
\hline
\end{tabular}

An analysis of Table 2 reveals that mean scores above 3.5 were computed on the dimensions of Internet marketing paybacks. These were; Intelligence gathering $(\bar{x}=5.579 ; p<0.05)$; Promotion $(\bar{x}=5.924 ; p<0.01)$; communication $(\bar{x}$ $=5.650 ; p<0.05)$ and Customer Relationship Management $(\bar{x}=5.051 ; p<0.05)$. These results show that among the five factors extracted, promotion seems to be the most important factor whereas customer relationship management seems to be the least important factor. The results of the Z-test also confirm that all factors extracted were significant, which further attests to their importance to Zimbabwean SMEs. Additionally, SME productivity $(\bar{x}=5.826 ; p<0.01)$ also emerged as an important factor to respondents.

\subsection{Correlation Analysis}

In order to determine the relationship between SME productivity and the four identified Internet Marketing benefits of Intelligence Gathering, Promotion, Communication and Customer Relationship Management, Pearson's Product-Moment correlation coefficients were computed. This correlation test statistic is used to describe the existence of a relationship between the four Internet Marketing dimensions and SME productivity, as well as the strength and direction of the association (Maxwell and Moores, 2007). The results are reported in Table 3. 
Table 3: Correlation analysis: Internet Marketing Benefits and SME productivity

\begin{tabular}{|l|c|c|c|c|c|}
\hline Dimension & $\begin{array}{c}\text { Intelligence } \\
\text { Gathering }\end{array}$ & Promotion & Communication & $\begin{array}{c}\text { Customer Relationship } \\
\text { Management }\end{array}$ & $\begin{array}{c}\text { SME } \\
\text { productivity }\end{array}$ \\
\hline Intelligence Gathering & 1.000 & $0.620^{* *}$ & $0.511^{* *}$ & $0.217^{*}$ & $0.623^{* *}$ \\
\hline Promotion & & 1.000 & $0.304^{*}$ & $0.612^{* *}$ & $0.645^{*}$ \\
\hline Communication & & & 1.000 & $0.296^{*}$ & $0.424^{* *}$ \\
\hline $\begin{array}{l}\text { Customer relationship } \\
\text { management }\end{array}$ & & & 1.000 & $0.341^{*}$ \\
\hline Productivity & & & & & 1.000 \\
\hline
\end{tabular}

Inter-factor correlations show that there were positive relationships between the four Internet marketing payback factors $(0.217 \leq r \leq 0.620)$. Furthermore, positive relationships $(0.341 \leq r \leq 0.6 .45)$ were observed between all four Internet payback sub-scales and SME productivity.

\subsection{Regression Analysis}

Multiple regression analysis is an inferential statistical technique that is performed to identify the variables that predict or provide the best explanation for the portion of the total variance in the scores of the dependent variables (Malhotra, 2010). In this study, regression analysis using the 'enter' method was conducted with a view to establish the existence of causality between these predictors (Internet marketing paybacks) and their relative measurement response (SME productivity)

Table 4: Regression Model: Internet Marketing benefit dimensions and SME Productivity

\begin{tabular}{|c|c|c|c|c|c|}
\hline \multirow{3}{*}{$\begin{array}{l}\text { Independent variables: } \\
\text { Internet Marketing dimensions }\end{array}$} & \multicolumn{5}{|c|}{ Dependent variable: SME Productivity } \\
\hline & \multirow{2}{*}{$\begin{array}{c}\text { Standardised Coefficients } \\
\text { Beta }\end{array}$} & \multirow{2}{*}{$t$} & \multirow{2}{*}{ Sig. } & \multicolumn{2}{|c|}{ Collinearity Statistics } \\
\hline & & & & Tolerance & VIF \\
\hline Intelligence Gathering & 0.470 & 4.240 & 0.000 & 0.371 & 1.943 \\
\hline Promotion & 0.368 & 5.825 & 0.021 & 0.282 & 1.628 \\
\hline Communication & 0.284 & 3.945 & 0.016 & 0.639 & 1.615 \\
\hline Customer relationship management & -0.116 & 2.637 & 0.523 & 0.509 & 1.036 \\
\hline
\end{tabular}

The four Internet marketing paybacks factors accounted for approximately $44 \%\left(R^{2}=0.438\right)$ of the variance explained in productivity. All tolerance values fell above the prescribed value of 0.5 (O'Brien, 2007) and variance inflation factor (VIF) values for all four factors values ranged between 1.0 and 4.0, as recommended by Pan and Jackson (2008). Since colleniarity statistics for the four Internet payback factors were acceptable, multi-co linearity was not a problem in the present study as the independent variables were not highly correlated.

\section{Discussion}

There was a strong positive association $(r=0.623 ; p<0.01)$ between intelligence gathering and SME productivity. The results of the regression analysis also reveal that intelligence gathering is a statistically significant predictor of SME productivity $(\beta=0.470 ; t=4.240 ; p<0.01)$. These results illustrate that an increase in intelligence gathering activities by SMEs also invokes an increase in SME productivity, and that the level of intelligence gathering in an SME can be a strong indicator of the level of productivity in that SME. Consistent with these findings, Dholakia and Kshetri (2004) concur that there is a direct influential relationship between Internet marketing and productivity in organisations. As further suggested by Simpson and Docherty (2004) the adoption of Internet marketing technologies enables SMEs to deliver critical information through platforms such as mailing lists, newsgroups and chat rooms to their internal stakeholders (employees) as well as external parties (suppliers, distributors and customers). This has a direct bearing on organisational outcomes, inclusive of both employee and organisational productivity (Palmer et al., 2012). SMEs that use Internet platforms are better equipped to enhance firm productivity through a plethora of intelligence gathering tools such as analyses of product innovations, industry trends' analysis, surveys of changing customer tastes and preferences as well as competitor and supplier analyses (Loane, 2005). It appears then, that intelligence gathering remains an internet marketing factor that positively impacts on productivity among SMEs.

A strong positive association $(r=0.645 ; p<0.01)$ was observed between SME productivity and the promotion factor. 
Promotion emerged as a statistically significant predictor of SME productivity $(\beta=0.368 ; t=5.825 ; p<0.05)$ demonstrating that SME throughput can be significantly enhanced through various elaborate online promotional campaigns. Consistently, Hongyu and Dongmei (2011) suggest that the systematic adoption of online promotion used in conjunction with offline promotional tools within the firm's overall marketing strategy could help to build a consistent brand image for the company. Online promotion is also a useful tool for the evaluation of the effectiveness of SME marketing communication activities (Dart, 2002; Kalaignanam et al., 2008). This is because web-based promotion has been proven to be a dominating SME approach which leads to accelerated SME growth and productivity through wider access and reach of the target markets (Beheshti and Sangari, 2007). Therefore, the interactive idiosyncrasies that are inherent in the online promotional platforms will generally present Internet based promotions as the $21^{\text {st }}$ century hallmark of business success; an element that is non-existent in many offline promotional platforms (Varadarajan and Yadav, 2009). Additionally, Palmer et al. (2012) emphasise that pressure from consumers has mandated SMEs to pay considerable attention to web-based promotional tools, such as social networking sites. This implies then that websites and other webbased tools derived from third generation web application (Web 3.0), such as Facebook, Twitter and YouTube may be systematically adopted by various SMEs for promotional purposes, with the intention of boosting productivity.

A moderate positive association $(r=0.424 ; p<0.05)$ was observed between communication and SME productivity. The Regression model further revealed that communication is a statistically significant predictor of SME productivity $(\beta=$ $0.284 ; t=3.945 ; p>0.05)$. This result suggests that an increase in communication as a benefit of Internet marketing adoption also triggers moderate increases in SME productivity. This finding is in agreement with previous research (e.g. Riquelme, 2002) who found positive linkages between Internet marketing communications and productivity. Klerk and Kroon (2005) also opine that the adoption of Internet marketing communication technologies leads to spatial effectiveness through the development of a global market place, leading to improvements in productivity and organisational performance. By communicating through the Internet, SMEs may realise significant reductions in operational costs of the business through 'disintermediation' (Mutula, 2002; Riquelme, 2002). Furthermore, Internet marketing communication has been found to be a direct antecedent to enhanced productivity of SME managers (Chaston and Mangles, 2003) as well as increased market share and earnings growth rate (Varadarajan and Yadav, 2009). Therefore, the communication abilities stemming from adoption of Internet marketing by a business has a stimulus effect on business, leading to the potential enhancement of competitive advantage and overall productivity.

The correlation matrix showed a weak relationship $(r=0.341 ; p<0.05)$ between customer relationship management and SME productivity. In the regression analysis, customer relationship management also emerged as an insignificant predictor of SME productivity $(\beta=-0.116 ; t=2.637 ; p>0.05)$. The results of the current study suggest that the influence of customer relationship management on SME productivity is weak and insignificant within the context of Zimbabwean SMEs. Electronic Customer Relationship Management (e-CRM) is the tool by which companies track, manage and increase relationships with their customers and it as crucial today as accounting and inventory software (Kristin and Kerr, 2002). Customer Relationship Management (CRM) may be defined as the process of understanding the nature of the exchange between the customer and supplier and managing it appropriately through beneficial communication exchanges that are optimised with a view to ensuring profitable long-term relationships (Ueno, 2006). CRM is a key focus for many organisations now as a shift away from customer acquisition toward customer-retention and churn reduction strategies and productivity enhancement among SMEs dictates a need for best practice CRM processes. However, the CRM revolution is not limited to CRM systems only, but also includes many business operations such as email and project management, social media tracking, invoicing software, phone management, file management, design and programming software and every component that is seemingly vital to running a successful business. The ability to effectively track and engage an audience allows companies to close leads and increase recurring customer sales (Ueno, 2006).

Interestingly, the results of the current study contradict the findings of previous studies by Dholakia and Kshetri (2004) and by Varadarajan and Yadav (2009) who found that strong and significant relationships between SME productivity and customer relationship management. The unexpected findings of the current study could be attributed to the fact that a majority of the e-CRM packages are large-scale integration technologies that are frequently supplied by external software vendors (Kristin and Kerr, 2002). As such, this could logically put a strain on the financial position of the small or medium sized firm (initially) as well as the time resources that should essentially be expended in the implementation of such technologies. However, some critics of e-CRM have cited the limited value addition of the vendorbased software packages that usually deliver generic productivity enhancing solutions (Ueno, 2006). This could therefore, seldom meet the specific requirements of some Zimbabwean SMEs who may be in need of tailor-made e-CRM solutions. In addition, the seamless, collaborative and organised nature of e-CRM plausibly requires an organisation-wide cultural overhaul which most employees may be unwilling to invest in. In this regard, the positive productivity and efficiency 
outcomes of the CRM benefit dimension may not necessarily be realised by the SMES.

\section{Conclusions and Recommendations}

This study was initiated to serve two intertwined purposes. The primary purpose was to identify the paybacks of Internet marketing to SMEs in Zimbabwe. Four factors; namely, intelligence gathering, promotion, communication and customer relationship management, were identified. Among these four factors, it emerged that promotion is the most important factor, followed by communication and intelligence gathering, with customer relationship management being the least important factor. The secondary purpose of the study was to examine the relationship between each Internet marketing payback factor with SME productivity. It emerged that there were strong and significant relationships between SME productivity and two factors; namely, intelligence gathering and promotion. A moderate significant relationship was observed between SME productivity and communication. The relationship between SME productivity and customer relationship management was weak. However, only three of the four identified factors; namely, intelligence gathering, promotion and communication significantly predicted SME productivity.

In the adoption of Internet Marketing, it is fundamental to ensure that SME managers are presented with an impeccable and cohesive conception of the pertinent paybacks of the electronic marketing tools. This is done through deliberate training and development programmes. If a firm adopts technological innovations without a clear understanding of the scope and implications of that adoption, insufficient attention may be paid to realigning the business strategy and acquisition of resources needed to achieve competitive advantage from the Internet marketing investment (Pires and Aisbett, 2003). Although the Ministry of Small and Medium enterprise as well as ZimTrade offer these courses, but they should also be accessible to those organisations with seemingly great potential though with limited financial bases. In a similar vein, management should ensure that their Marketing personnel are trained and equipped with the appropriate IT skills to meet the innovative needs of the modern customers and thus keep abreast of changing technological developments.

\section{Limitations and Directions for Future Research}

This study has several limitations, which must be acknowledged. First, the study used a limited sample size of 189 SMEs. For a developing country such as Zimbabwe, whose economy is largely driven by the SME sector, this sample size may be considered as insufficient. As such, caution should be exercised when generalizing the findings of the current study to other contexts. In line with this notion, more engaging surveys may be conducted using amplified sample sizes or within other provinces of Zimbabwe. In addition to enhancing the generalizability of the study, such research efforts may also provide room for comparative studies amongst the different provinces within the country. Second, the sample was selected among SMEs in bona fide industrial areas only, since it was it was difficult to account for SMEs that are located within residential areas. Future studies could also manipulate this gap.

A third limitation of the study is that the instrument used in this study was a synthesis of questions that were adapted from previous studies. This presents a number of latent limitations to the methodology used in this study, since the other questionnaires were originally designed for different purposes and settings. It would be interesting then, to conduct future studies using a questionnaire that was originally intended for this study rather than hybrid adaptations. Moreover, the use of the convenience sampling approach naturally enhanced the study's susceptibility to sampling bias. As such, future studies could also be based on probability sampling techniques, which present all SMEs with an equal opportunity to participate in the survey. Future studies could also explore the benefits of Internet marketing among large enterprises in Zimbabwe. This could facilitate effective benchmarking between SMEs and larger enterprises in the area of Internet marketing. Finally, it has to be appreciated that the paybacks of Internet marketing are not limited to the dimensions identified in this study. This being the case, future studies could seek to examine the structural interplay between other identified Internet marketing paybacks and various organisational outcomes.

\section{References}

Asli Demirguç-Kunt, B. and Maksimovic, V. (2005). Marketing communications: contexts, strategies and applications. $3^{\text {rd }}$ ed, Financial Times Prentice Hall, Harlow.

Bamba, F. and Barnes, S. J. (2007) SMS advertising, permission and the consumer: a study, Business Process Management Journal, 13(6): 815-829.

Beaver, A. (2002) Creating a climate for change: the case for media neutral planning and how to get there [online], ATG UK. Available 
from: http://www.marketingsociety.org.uk/downloads/climate-change-mnp.pdf. Accessed on 11 August 2013.

Beheshti, H. M. and Sangari, E. S. (2007). The benefits of e-business adoption an empirical study of Swedish SMEs. Service Business Journal, 1(3): 233-245

Berril, A., Goode, S. and Hart D. (2004). Managerial expectations of Internet commerce adoption after the tech wreck. Journal of Global Information Technology Management, 7(3): 45-63.

Biedenbach, M., and Marell, H. (2009). Integrated marketing communications in the Australian and New Zealand wine industry. International Journal of Advertising, 20(2): 239-262.

Burgess, S. M. and Bothma, C. H. (2007). International marketing. Cape Town: Oxford University Press.

Chaston, I. and Mangles, T. (2003). Relationship marketing in online business to business markets: a pilot investigation of small UK manufacturing firms. European Journal of Marketing, 37(5/6): 753-773.

Chong, W. K., Shafaghi, M. and Tan, B. L. (2011). Development of a business-to-business critical success factors (B2B CSFs) framework for Chinese SMEs. Marketing Intelligence and Planning Journal, 29(5): 517-530.

Daniel, E. and Wilson, H. (2002). Adoption intentions and benefits realised: a study of E-Commerce in UK SMEs. Journal of Small Business and Enterprise Development, 9(4): 331-348.

Dart, C. (2002) Internet marketing: new millennia. Available: http://www.nextwavemultimedia.com/html/pdf/emarketing_newmillenia. [Accessed October 2011].

Dholakia, R. R. and Kshetri, N. (2004). Factors impacting the adoption of the Internet among SMEs. Small Business Economics, 23(1): 311-322.

Drew, S. (2003). Strategic uses of E-Commerce by SMEs in the east of England. European Management Journal, 21(1), 79-88.

Grandon, E. and Pearson, J. (2003). Strategic value and adoption of electronic commerce: An empirical study of Chilean small and medium sized businesses. Journal of Global Information Technology Management, 6(3):22-43.

Gohary, H. (2007). The effects of E-Marketing on the marketing performance of Small Business Enterprises: a comparative study between Egypt and U.K. Paper presented at the 16 th EDAMBA Summer Academy held in France in July 2007. France.

Harrison, T. and Waite, K. (2006). A time based assessment of the influences, uses, and benefits of Intermediary website adoption. Journal of Information and Management, 43(1): 1002-1013.

Hasnu, S. A. F. and Amjad, S. (2006). LPN-BSN: ICT, Small enterprise strategic management and performance: a theoretical model with some UK evidence. [Online]. Available at: <http://www.bradford.ac.uk/acad>. Accessed on 31 March 2013.

Hongyu, W. and Dongmei, Z. (2011). Internet technology's development and its positive role in promoting E-Marketing. Energy Procedia, 5: 6504-6507.

Jutla, D., Bodorick, P. and Dhaliwal, J. (2002), Supporting the E-readiness of small and medium sized enterprises: approaches and metrics. Internet Research: Electronic Networking Applications and Policy, 12(2): 139-164.

Kalaignanam, K., Kushwaha, T. and Varadarajan, P. (2008). Marketing operations efficiency and the Internet: An organising framework. Journal of Business Research, 61(1): 300-308.

Kendall, J. D., Tung, L.L., Chua, K. H., Dennis, N. G. C. H. and Tan, S. M. (2001). Receptivity of Singapore's SMEs to electronic commerce adoption. Journal of strategic information systems, 10: 223-242.

Klerk, De.S. and Kroon, J. (2005). E-commerce adoption in South African businesses. South African Journal of Business Management, 36(1): 33-40.

Kristin, A. and Kerr, C. (2002). Customer relationship management. McGraw-Hill, New York:

Kohn, S. and Husig, S. (2006). Potential benefits, current supply, utilization and barriers to adoption: an exploratory study of German SMEs. Technovation, 26(1): 988-998.

Kotler, P. (2006). Integrated advertising, promotion, and marketing communications. London: Prentice Hall.

Lewis, R. and Cockrill, A. (2002). Going global- remaining local: the impact of e-commerce on small retail firm in Wales. International Journal of Information Management, 22: 195-209.

Loane, S. (2005). The role of the internet in the internationalisation of small and medium sized companies. Journal of International Entrepreneurship, 3(4): 263-277.

Maxwell, J. P. and Moores, E., (2007). The development of a short scale measuring aggressiveness and anger in competitive athletes. Psychology of Sport and Exercise, 8: 179-193.

Melewar, T. C. and Smith, N. (2003). The Internet revolution, some global marketing implications, Marketing Intelligence Planning, 21(6): 363-369.

Moodley, S. (2003). The challenge of E-Business for the South African apparel sector. Technovation, 23: 557-570.

Morgan, M. J., Lawley, M. and Spinks, W. (2006). Internet marketing strategy: an exploratory investigation into Chinese business use of the Internet. Paper read at the Australian and New Zealand Marketing Academy (ANZMAC) Conference on Advancing Theory, Maintaining Relevance held in Brisbane, Australia on 4 to 6 December 2006: Australia.

Moyo, R. (2010). First Report of the portfolio committee on small and medium cooperative development on the status of small and medium enterprises cooperative development in Harare third session - seventh parliament presented to parliament on 2010 available on accessed on 23/11/12. [Online] Available at: http://www.parlzim.gov.zw/attachments/article/54/Small\%20and\%20 Medium\%20Enterprise\%20Cooperative\%20Development\%20_Report\%20\%20of\%20SMEs.pdf. Accessed on 5 September 2013.

Mukti, N. (2000). Barriers to putting business on the Internet in Malaysia, Journal of Information Systems in Developing Countries, 2(6): 1-6.

Mutambanengwe, F. (2012). Obstacles to SME Success in Zimbabwe: Financial Talk. 2012 Website Accessed On 15/11/12. [Online] 
Available: www.allafrica.com/stories/201204210167.html. Accessed on 10 September 2013.

Mutula, S. M. (2002). Current developments in the Internet industry in Botswana. The Electronic Library Journal, 20(6): 504-511.

O'Brien, R. M. (2007). A caution regarding rules of thumb for variance inflation factors. Quality \& Quantity, 41: 673-690.

Palmer, D. W., Ellinger, A. E., Allaway, A. and D'Souza, G. (2012). A longitudinal examination of internet-based customer service system usage in small companies. Journal of Business and Industrial Marketing, 27(1): 29-40.

Pan, Y. and Jackson, R. T. (2008). Ethnic difference in the relationship between acute inflammation and serum ferritin in US adult males. Epidemiology and Infection, 136: 421-431.

Pires, G.D., Aisbett, J. (2003). The relationship between technology adoption and strategy in business to business markets: the case of E-Commerce. Industrial Marketing Management Journal, 32(4): 291-300.

Ramsey, E. and McCole, P. (2005). E-Business in professional SMEs: the case of New Zealand. Journal of Small Business and Enterprise Development, 12(4): 528-544.

Rao, S.S., Metts, G. and Monge, C. A. M. (2003). Electronic Commerce development in small and medium enterprises; a stage model and its implications. A Business Process Management Journal, 9(1): 11-32.

Republic of Zimbabwe. (2002). The Development Framework of Small and Medium Scale Enterprises in Zimbabwe, Government Printers: Harare.

Riquelme, H. (2002). Commercial Internet adoption in China; comparing the experience of small, medium and large businesses. Internet Research: Electronic Networking Applications and Policy, 12(3): 276-286.

Sharma, G. R. K. and Arya, H. P. S. (2006). Availability and utility of Internet sources of information: farmers' perceptions. South African Computing Journal, 37(1): 5-80.

Sheth, J. N. and Sharma, A. (2005). International E-Marketing: opportunities and issues, International Marketing Review, 22(6): 611622.

Simpson, M. and Docherty, A. J. (2004). E-commerce adoption, support and advice for UK SMEs. Journal of Small Business and Enterprise Development, 11(3): 315-328.

Soontiens, W. (2002). Managing International Trade: an analysis of South African SMEs and regional trade. Journal of Management Decisions, 40(7): 710-719.

Tsikirayi, C. M. R., Muchenje, B. and Katsidzira, Z. (2013). Impact of integrated marketing communications mix (IMCM) in Small to Medium Enterprises (SMEs) in Zimbabwe as a marketing tool. Research in Business and Economics Journal, 7(10): 1-12.

Ueno, S. (2006). The impact of customer relationship management, occasional paper on the US-Japan international Relations Program. Harvard University: USA.

Varadarajan, R., Yadav, M. S. (2009) Marketing strategy in an internet-enabled environment: a retrospective on the first ten years of JIM and a prospective on the next ten years. Journal of Interactive Marketing, 23: 11-22.

Welman, J. C. and Kruger, S. J. (1999). Research methodology. $2^{\text {nd }}$ ed. University Press, Oxford.

Zappala, S. and Gray, C. (2006). Impact of E-Commerce on consumers and small firms. Hampshire: Ashgate publishers. 